PROCEEDINGS OF THE

AMERICAN MATHEMATICAL SOCIETY

Volume 126, Number 2, February 1998, Pages 365-374

S 0002-9939(98)04264-6

\title{
UNIQUENESS OF POSITIVE SOLUTIONS FOR STURM-LIOUVILLE BOUNDARY VALUE PROBLEMS
}

\author{
FU-HSIANG WONG
}

(Communicated by Hal L. Smith)

\begin{abstract}
Sufficient conditions for the uniqueness of positive solutions of singular Sturm-Liouville boundary value problems

$(\mathrm{BVP})$

$$
\left\{\begin{array}{l}
(\mathrm{E})\left(\left|u^{\prime}\right|{ }^{m-2} u^{\prime}\right)^{\prime}+f\left(t, u, u^{\prime}\right)=0, \quad \text { in }\left(\theta_{1}, \theta_{2}\right), m \geq 2, \\
\text { (BC) }\left\{\begin{array}{l}
\alpha_{1} u\left(\theta_{1}\right)-\beta_{1} u^{\prime}\left(\theta_{1}\right)=0, \\
\alpha_{2} u\left(\theta_{2}\right)+\beta_{2} u^{\prime}\left(\theta_{2}\right)=0,
\end{array}\right.
\end{array}\right.
$$
\end{abstract}

where $\alpha_{i}, \beta_{i} \geq 0$ and $\alpha_{i}^{2}+\beta_{i}^{2} \neq 0(i=1,2)$, are established.

\section{INTRODUCTION}

In this paper, we are concerned with the uniqueness of positive solutions of boundary value problems for the nonlinear differential equation

$$
\left(\left|u^{\prime}\right|^{m-2} u^{\prime}\right)^{\prime}+f\left(t, u, u^{\prime}\right)=0, \quad \theta_{1}<t<\theta_{2}, m \geq 2
$$

subject to one of the following sets of boundary conditions:

$$
\begin{aligned}
& u\left(\theta_{1}\right)=\xi_{1} \geq 0, \quad u^{\prime}\left(\theta_{2}\right)=\xi_{2} \geq 0, \\
& u^{\prime}\left(\theta_{1}\right)=\xi_{1} \leq 0, \quad u\left(\theta_{2}\right)=\xi_{2} \geq 0, \\
& u\left(\theta_{1}\right)=\xi_{1} \geq 0, \quad u\left(\theta_{2}\right)=\xi_{2} \geq 0,
\end{aligned}
$$

where $m \geq 2,\left(\theta_{1}, \theta_{2}\right) \subseteq(-\infty, \infty)$ and $f:\left(\theta_{1}, \theta_{2}\right) \times(0, \infty) \times(-\infty, \infty) \rightarrow(0, \infty)$ satisfies

$f(t, x, y)$ is locally Lipschitz continuous for $(x, y)$ in $(0, \infty) \times\{(-\infty, 0) \cup(0, \infty)\} ; f(t, x, y) / x^{m-1}$ is strictly decreasing with respect to $x \in(0, \infty)$ for each fixed $(t, y) \in\left(\theta_{1}, \theta_{2}\right) \times(-\infty, \infty)$; and $\operatorname{sgn}(y) f(t, x, y)$ is decreasing with respect to $y \in(-\infty, \infty)$ for each fixed $(t, x) \in\left(\theta_{1}, \theta_{2}\right) \times(0, \infty)$.

Received by the editors April 17, 1996.

1991 Mathematics Subject Classification. Primary 34B15; Secondary 35J25, 35J65, 47H15.

Key words and phrases. Sturm-Liouville BVPs, positive solution, singular and uniqueness. 
Furthermore, we use the uniqueness theorems of (E) with respect to the boundary conditions (BC. $i)(i=1,2,3)$ to show that

$$
\left\{\begin{array}{l}
(\mathrm{E})\left(\left|u^{\prime}\right|^{m-2} u^{\prime}\right)^{\prime}+f\left(t, u, u^{\prime}\right)=0, \quad \text { in }\left(\theta_{1}, \theta_{2}\right), m \geq 2, \\
(\mathrm{BC})\left\{\begin{array}{l}
\alpha_{1} u\left(\theta_{1}\right)-\beta_{1} u^{\prime}\left(\theta_{1}\right)=0, \\
\alpha_{2} u\left(\theta_{2}\right)+\beta_{2} u^{\prime}\left(\theta_{2}\right)=0,
\end{array}\right.
\end{array}\right.
$$

where $\alpha_{i}, \beta_{i} \geq 0$ and $\alpha_{i}^{2}+\beta_{i}^{2} \neq 0(i=1,2)$ has at most one positive solution in $C^{1}\left(\left[\theta_{1}, \theta_{2}\right]\right)$.

Equations of the type (E) arise in studies of radially symmetric solutions (i.e., solutions $u$ that depend only on the variable $r=|x|$ ) of the $m$-Laplace equation,

$\left(\mathrm{E}_{1}\right) \quad \nabla \cdot\left(|\nabla u|^{m-2} \nabla u\right)+g(|x|, u, \nabla u)=0, \quad R_{0}<|x|<R_{1}, x \in \mathbb{R}^{N}, N \geq 2$.

A radially symmetric solution of $\left(E_{1}\right)$ satisfies the ordinary differential equation

$$
\left(\left|u^{\prime}\right|^{m-2} u^{\prime}\right)^{\prime}+\frac{N-1}{r}\left|u^{\prime}\right|^{m-2} u^{\prime}+g\left(r, u, u^{\prime}\right)=0, \quad R_{0}<r<R_{1} .
$$

With the change of variables $t=r^{\frac{m-N}{m-1}}($ for $m \neq N)$ or $t=\log r($ for $m=N)$, equation $\left(\mathrm{E}_{2}\right)$ can be reduced to an equation of the type $(\mathrm{E})$ or

$$
(m-1)\left|u^{\prime}\right|^{m-2} u^{\prime \prime}+f\left(t, u, u^{\prime}\right)=0, \quad \theta_{1}<t<\theta_{2}, m \geq 2 .
$$

Conditions for the existence of solutions of equation (E) with respect to (BC.1)(BC.3) were studied by many authors; see for instance, De Figueiredo, Lions and Nussbaum [6], Granas, Guenther and Lee [9], Kaper, Knaap and Kwong [12], Lions [16], del Pino, Elgueta and Manasevich [19], Rabinowitz [21], Wong [24], and the references therein. The uniqueness problem concerning $(\mathrm{E})$, for the case $m=2$, has been studied by many authors. For example, Gatica, Oliker and Waltman [7], Kwong [14], Dalmasso [4, 5], Brezis and Oswald [3], Krasnoselskii [13], and the excellent book by Agarwal and Lakshmikantham [1]. However, it seems that very little is known for the case $m \neq 2$. Recently, Naito [17] considered the case $f\left(t, u, u^{\prime}\right)=p(t) f(u)$ and established some excellent conditions for uniqueness by using the generalized Prüfer transformation and comparison theorems. In this article, the author attempts to afford a concise approach to study the uniqueness of positive solutions of (E) with boundary conditions (BC.1)-(BC.3) and (BC).

For other related results, we refer the reader to Bobisud [2], Dalmasso [4, 5] Guedda and Veron [10], Naito [17], del Pino and Manasevich [20], O'Regan [22], and Wong and $\mathrm{Yu}[23]$.

\section{MAIN RESUlt}

Let $u$ and $v$ be two distinct positive solutions of (E). We define

$$
w(t):=\{u(t)\}^{m-1}\left(\left|v^{\prime}(t)\right|^{m-2} v^{\prime}(t)\right)-\left(\left|u^{\prime}(t)\right|^{m-2} u^{\prime}(t)\right)\{v(t)\}^{m-1}
$$

for $t \in[a, b] \subseteq\left[\theta_{1}, \theta_{2}\right]$. 
It is clear that $w(t)$ satisfies

$$
\begin{aligned}
w^{\prime}(t)= & u^{m-1}\left(\left|v^{\prime}\right|^{m-2} v^{\prime}\right)^{\prime}-\left(\left|u^{\prime}\right|^{m-2} u^{\prime}\right)^{\prime} v^{m-1} \\
& +(m-1) u^{\prime} v^{\prime}\left\{\left|v^{\prime}\right|^{m-2} u^{m-2}-\left|u^{\prime}\right|^{m-2} v^{m-2}\right\} \\
= & u^{m-1}\left\{-f\left(t, v, v^{\prime}\right)\right\}-\left\{-f\left(t, u, u^{\prime}\right)\right\} v^{m-1} \\
& +(m-1) u^{\prime} v^{\prime}\left\{\left|v^{\prime} u\right|^{m-2}-\left|u^{\prime} v\right|^{m-2}\right\} \\
= & (u v)^{m-1}\left\{\frac{f\left(t, u, u^{\prime}\right)}{u^{m-1}}-\frac{f\left(t, v, v^{\prime}\right)}{v^{m-1}}\right\} \\
& +(m-1) u^{\prime} v^{\prime}\left\{\left|v^{\prime} u\right|^{m-2}-\left|u^{\prime} v\right|^{m-2}\right\} \\
= & (u v)^{m-1}\left\{\frac{f\left(t, u, u^{\prime}\right)}{u^{m-1}}-\frac{f\left(t, v, u^{\prime}\right)}{v^{m-1}}+\frac{f\left(t, v, u^{\prime}\right)}{v^{m-1}}-\frac{f\left(t, v, v^{\prime}\right)}{v^{m-1}}\right\} \\
& +(m-1) u^{\prime} v^{\prime}\left\{\left|v^{\prime} u\right|^{m-2}-\left|u^{\prime} v\right|^{m-2}\right\}
\end{aligned}
$$

for $t \in(a, b) \subseteq\left(\theta_{1}, \theta_{2}\right)$.

In order to treat our main results, we need the following:

Lemma 2.1. Let $u$ and $v$ be distinct positive solutions of $(\mathrm{E})-(\mathrm{BC} . i)$ in $C^{1}\left(\left[\theta_{1}, \theta_{2}\right]\right)$ and $u>v$ on $\left(\theta_{1}, \theta_{2}\right)$ for $i=1,2,3$. Then $w^{\prime}(t)<0$ in $\left(\theta_{1}, \theta_{2}\right)$, that is, $w(t)$ is strictly decreasing in $\left[\theta_{1}, \theta_{2}\right]$.

Proof. We separate the proof into the following cases:

Case (1). Suppose that $u$ and $v$ are two distinct positive solutions of (E)-(BC.1). First, we claim that $u^{\prime}(t) v(t) \geq v^{\prime}(t) u(t)(\geq 0)$ in $\left[\theta_{1}, \theta_{2}\right]$.

$\left(1^{\circ}\right)$ Assume that there exists $t_{1} \in\left(\theta_{1}, \theta_{2}\right)$ such that

$$
u^{\prime}(t) v(t) \geq v^{\prime}(t) u(t)(\geq 0) \text { on }\left[\theta_{1}, t_{1}\right) \text { and } u^{\prime}\left(t_{1}\right) v\left(t_{1}\right)=v^{\prime}\left(t_{1}\right) u\left(t_{1}\right)(\geq 0),
$$

which imply $u^{\prime}(t) \geq v^{\prime}(t)(\geq 0)$ on $\left[\theta_{1}, t_{1}\right]$. It follows from $(2), f(t, x, y) / x^{m-1}$ is strictly decreasing with respect to $x \in(0, \infty)$ and $f(\cdot, \cdot, y)$ is decreasing in $(0, \infty)$ that $w^{\prime}(t)<0$ on $\left(\theta_{1}, t_{1}\right)$. Thus $w(t)$ is a strictly decreasing function on $\left[\theta_{1}, t_{1}\right]$. Therefore

$$
\begin{aligned}
0 & =\left(v^{\prime}\left(t_{1}\right) u\left(t_{1}\right)\right)^{m-1}-\left(u^{\prime}\left(t_{1}\right) v\left(t_{1}\right)\right)^{m-1}=w\left(t_{1}\right) \\
& <w\left(\theta_{1}\right)=\left\{u\left(\theta_{1}\right)\right\}^{m-1}\left[\left|v^{\prime}\left(\theta_{1}\right)\right|^{m-2} v^{\prime}\left(\theta_{1}\right)-\left|u^{\prime}\left(\theta_{1}\right)\right|^{m-2} u^{\prime}\left(\theta_{1}\right)\right] \leq 0,
\end{aligned}
$$

which gives a contradiction.

$\left(2^{\circ}\right)$ Assume that there exists a strictly decreasing sequence $\left\{t_{n}\right\}_{n=1}^{\infty}$ satisfying $\lim _{n \rightarrow \infty} t_{n}=\theta_{1},\left(u^{\prime} v-v^{\prime} u\right)\left(t_{n}\right)=0,\left(u^{\prime} v-v^{\prime} u\right)^{\prime}\left(t_{2 n}\right)=\left(u^{\prime \prime} v-v^{\prime \prime} u\right)\left(t_{2 n}\right) \leq 0$ and $\left(u^{\prime} v-v^{\prime} u\right)^{\prime}\left(t_{2 n-1}\right)=\left(u^{\prime \prime} v-v^{\prime \prime} u\right)\left(t_{2 n-1}\right) \geq 0$ for all $n \in \mathbb{N}$. It follows from $\left(\mathrm{E}^{*}\right)$, (H) and $u^{\prime}\left(t_{2 n}\right) \geq v^{\prime}\left(t_{2 n}\right) \geq 0$ that

$$
\begin{aligned}
0 \geq & (m-1)\left|u^{\prime}\right|^{m-2} v^{m-2}\left(u^{\prime \prime} v-v^{\prime \prime} u\right)\left(t_{2 n}\right) \\
= & (u v)^{m-1}\left(t_{2 n}\right)\left\{\frac{f\left(t_{2 n}, v\left(t_{2 n}\right), v^{\prime}\left(t_{2 n}\right)\right)}{v^{m-1}\left(t_{2 n}\right)}-\frac{f\left(t_{2 n}, u\left(t_{2 n}\right), u^{\prime}\left(t_{2 n}\right)\right)}{u^{m-1}\left(t_{2 n}\right)}\right\} \\
= & (u v)^{m-1}\left(t_{2 n}\right)\left\{\frac{f\left(t_{2 n}, v\left(t_{2 n}\right), v^{\prime}\left(t_{2 n}\right)\right)}{v^{m-1}\left(t_{2 n}\right)}-\frac{f\left(t_{2 n}, u\left(t_{2 n}\right), v^{\prime}\left(t_{2 n}\right)\right)}{u^{m-1}\left(t_{2 n}\right)}\right\} \\
& +(u v)^{m-1}\left(t_{2 n}\right)\left\{\frac{f\left(t_{2 n}, u\left(t_{2 n}\right), v^{\prime}\left(t_{2 n}\right)\right)}{u^{m-1}\left(t_{2 n}\right)}-\frac{f\left(t_{2 n}, u\left(t_{2 n}\right), u^{\prime}\left(t_{2 n}\right)\right)}{u^{m-1}\left(t_{2 n}\right)}\right\}>0 .
\end{aligned}
$$

This gives a contradiction. Hence, we have $u^{\prime}(t) v(t) \geq v^{\prime}(t) u(t)(\geq 0)$ in $\left[\theta_{1}, \theta_{2}\right]$, which implies $w^{\prime}(t)<0$ in $\left(\theta_{1}, \theta_{2}\right)$. 
Case (2). Suppose that $u$ and $v$ are two distinct positive solutions of (E)-(BC.2). The proof is quite similar to Case (1), thus we omit the details.

Case (3). Suppose that $u$ and $v$ are two distinct positive solutions of (E)-(BC.3). By virtue of Case (1) and Case (2), we need only consider the case $u^{\prime}\left(\theta_{1}\right) \neq v^{\prime}\left(\theta_{1}\right)$ and $u^{\prime}\left(\theta_{2}\right) \neq v^{\prime}\left(\theta_{2}\right)$. Without loss of generality, we may assume that $\xi_{1} \leq \xi_{2}$ (resp. $\left.\xi_{2} \leq \xi_{1}\right)$, which implies $u^{\prime}\left(\theta_{1}\right)>v^{\prime}\left(\theta_{1}\right) \geq 0$ (resp. $u^{\prime}\left(\theta_{2}\right)<v^{\prime}\left(\theta_{2}\right) \leq 0$ ).

$\left(3^{\circ}\right)$ Assume that there exist $t_{1}, t_{2} \in\left(\theta_{1}, \theta_{2}\right)$ such that $u^{\prime}\left(t_{1}\right)=v^{\prime}\left(t_{2}\right)=0$. Since $\left|u^{\prime}\right|^{m-2} u^{\prime}$ and $\left|v^{\prime}\right|^{m-2} v^{\prime}$ are strictly decreasing in $\left(\theta_{1}, \theta_{2}\right), t_{1}$ and $t_{2}$ are determined uniquely. If $t_{1}<t_{2}$, it follows from $u^{\prime}\left(\theta_{1}\right)>v^{\prime}\left(\theta_{1}\right) \geq 0$ and $u^{\prime}\left(t_{1}\right)=0<v^{\prime}\left(t_{1}\right)$ that there exists $t_{3} \in\left(\theta_{1}, t_{1}\right)$ satisfying

$$
u^{\prime}(t)>v^{\prime}(t)>0 \text { on }\left[\theta_{1}, t_{3}\right) \text { and } u^{\prime}\left(t_{3}\right)=v^{\prime}\left(t_{3}\right)>0 .
$$

It follows from $u\left(\theta_{1}\right)=v\left(\theta_{1}\right)=\xi_{1} \geq 0, u^{\prime}\left(t_{3}\right)=v^{\prime}\left(t_{3}\right)>0$ and Case (1) that $w^{\prime}(t)<$ 0 on $\left(\theta_{1}, t_{3}\right)$. Thus $w(t)$ is a strictly decreasing function on $\left[\theta_{1}, t_{3}\right]$. Therefore

$$
\begin{aligned}
0 & <\left\{u^{\prime}\left(t_{3}\right)\right\}^{m-1}\left[\left\{u\left(t_{3}\right)\right\}^{m-1}-\left\{v\left(t_{3}\right)\right\}^{m-1}\right]=w\left(t_{3}\right) \\
& <w\left(\theta_{1}\right)=\left\{u\left(\theta_{1}\right)\right\}^{m-1}\left[\left|v^{\prime}\left(\theta_{1}\right)\right|^{m-2} v^{\prime}\left(\theta_{1}\right)-\left|u^{\prime}\left(\theta_{1}\right)\right|^{m-2} u^{\prime}\left(\theta_{1}\right)\right] \leq 0,
\end{aligned}
$$

which gives a contradiction. If $t_{1}>t_{2}$, it follows from $u^{\prime}\left(\theta_{2}\right)<v^{\prime}\left(\theta_{2}\right) \leq 0$ and $v^{\prime}\left(t_{1}\right)<0=u^{\prime}\left(t_{1}\right)$ that there exists $t_{4} \in\left(t_{1}, \theta_{2}\right)$ such that

$$
u^{\prime}\left(t_{4}\right)=v^{\prime}\left(t_{4}\right)<0 \quad \text { and } \quad u^{\prime}(t)<v^{\prime}(t) \leq 0 \text { on }\left(t_{4}, \theta_{2}\right] .
$$

It follows from $u\left(\theta_{2}\right)=v\left(\theta_{2}\right)=\xi_{2} \geq 0, u^{\prime}\left(t_{4}\right)=v^{\prime}\left(t_{4}\right)<0$ and Case (2) that $w^{\prime}(t)<$ 0 on $\left(t_{4}, \theta_{2}\right)$. Thus $w(t)$ is a strictly decreasing function on $\left[t_{4}, \theta_{2}\right]$. Therefore

$$
\begin{aligned}
0 & \leq\left\{u\left(\theta_{2}\right)\right\}^{m-1}\left[\left|v^{\prime}\left(\theta_{2}\right)\right|^{m-2} v^{\prime}\left(\theta_{2}\right)-\left|u^{\prime}\left(\theta_{2}\right)\right|^{m-2} u^{\prime}\left(\theta_{2}\right)\right]=w\left(\theta_{2}\right) \\
& <w\left(t_{4}\right)=\left|u^{\prime}\left(t_{4}\right)\right|^{m-2} u^{\prime}\left(t_{4}\right)\left[\left\{u\left(t_{4}\right)\right\}^{m-1}-\left\{v\left(t_{4}\right)\right\}^{m-1}\right] \leq 0,
\end{aligned}
$$

which gives a contradiction, too. Thus, $t_{1}=t_{2}$. By Cases (1)-(2), we see that $w^{\prime}(t)<0$ in $\left(\theta_{1}, \theta_{2}\right)$.

$\left(4^{\circ}\right)$ Assume that there exists $t_{1} \in\left(\theta_{1}, \theta_{2}\right)$ such that $u^{\prime}\left(t_{1}\right)=0$ and $v^{\prime}(t) \neq 0$ in $\left(\theta_{1}, \theta_{2}\right)$. It follows from $u^{\prime}\left(\theta_{1}\right)>v^{\prime}\left(\theta_{1}\right)(\geq 0)$ and $u^{\prime}\left(t_{1}\right)=0<v^{\prime}\left(t_{1}\right)$ that there exists $t_{5} \in\left(\theta_{1}, t_{1}\right)$ satisfying

$$
u^{\prime}(t)>v^{\prime}(t)>0 \text { on }\left[\theta_{1}, t_{5}\right) \text { and } u^{\prime}\left(t_{5}\right)=v^{\prime}\left(t_{5}\right)>0 .
$$

Just as in the proof in $\left(3^{\circ}\right)$, we get a contradiction.

$\left(5^{\circ}\right)$ Assume that there exists $t_{2} \in\left(\theta_{1}, \theta_{2}\right)$ such that $v^{\prime}\left(t_{2}\right)=0$ and $u^{\prime}(t) \neq 0$ in $\left(\theta_{1}, \theta_{2}\right)$. Therefore, we obtain $0 \leq u^{\prime}\left(\theta_{2}\right)<v^{\prime}\left(\theta_{2}\right) \leq 0$, which gives a contradiction.

$\left(6^{\circ}\right)$ Assume that $u^{\prime}(t) \neq 0$ and $v^{\prime}(t) \neq 0$ in $\left(\theta_{1}, \theta_{2}\right)$. It follows from $u^{\prime}\left(\theta_{1}\right)>$ $v^{\prime}\left(\theta_{1}\right)(\geq 0)$ and $u^{\prime}\left(\theta_{2}\right)<v^{\prime}\left(\theta_{2}\right)(\geq 0)$ that there exists $t_{6} \in\left(\theta_{1}, \theta_{2}\right)$ satisfying

$$
u^{\prime}(t)>v^{\prime}(t)>0 \text { on }\left[\theta_{1}, t_{6}\right) \text { and } u^{\prime}\left(t_{6}\right)=v^{\prime}\left(t_{6}\right)>0 .
$$

Just as in the proof in $\left(3^{\circ}\right)$, we get a contradiction.

Theorem 2.2. The boundary value problem (E)-(BC.1) has at most one positive solution in $C^{1}\left(\left[\theta_{1}, \theta_{2}\right]\right)$.

Proof. Assume to the contrary that $u$ and $v$ are two distinct positive solutions of (E)-(BC.1). We claim that $u$ and $v$ intersect in $\left(\theta_{1}, \theta_{2}\right)$. Suppose, on the contrary, 
that $u(t)>v(t)$ in $\left(\theta_{1}, \theta_{2}\right)$. It follows from Lemma 2.1 and $u^{\prime}\left(\theta_{1}\right) \geq v^{\prime}\left(\theta_{1}\right)(\geq 0)$ that

$$
\begin{aligned}
0 & \leq\left[\left\{u\left(\theta_{2}\right)\right\}^{m-1}-\left\{v\left(\theta_{2}\right)\right\}^{m-1}\right]\left|v^{\prime}\left(\theta_{2}\right)\right|^{m-2} v^{\prime}\left(\theta_{2}\right)=w\left(\theta_{2}\right) \\
& <w\left(\theta_{1}\right)=\left\{u\left(\theta_{1}\right)\right\}^{m-1}\left[\left|v^{\prime}\left(\theta_{1}\right)\right|^{m-2} v^{\prime}\left(\theta_{1}\right)-\left|u^{\prime}\left(\theta_{1}\right)\right|^{m-2} u^{\prime}\left(\theta_{1}\right)\right] \leq 0
\end{aligned}
$$

which gives a contradiction. Hence, there exists $t_{1} \in\left(\theta_{1}, \theta_{2}\right)$ such that $u\left(t_{1}\right)=$ $v\left(t_{1}\right)>0$. Following from $u\left(t_{1}\right)=v\left(t_{1}\right)>0, u^{\prime}\left(\theta_{2}\right)=v^{\prime}\left(\theta_{2}\right)=\xi_{2} \geq 0$, and repeating the same process as above, we obtain a $t_{2} \in\left(t_{1}, \theta_{2}\right)$ such that $u\left(t_{2}\right)=$ $v\left(t_{2}\right)>0$.

Now, we claim that $u$ and $v$ intersect in $\left(t_{1}, t_{2}\right)$. Assume, on the contrary, that $u(t)>v(t)$ in $\left(t_{1}, t_{2}\right)$; then $u^{\prime}\left(t_{1}\right) \geq v^{\prime}\left(t_{1}\right) \geq 0$ and $0 \leq u^{\prime}\left(t_{2}\right) \leq v^{\prime}\left(t_{2}\right)$. From Lemma 2.1 we see that

$$
\begin{aligned}
0 & \leq\left\{u\left(t_{2}\right)\right\}^{m-1}\left[\left|v^{\prime}\left(t_{2}\right)\right|^{m-2} v^{\prime}\left(t_{2}\right)-\left|u^{\prime}\left(t_{2}\right)\right|^{m-2} u^{\prime}\left(t_{2}\right)\right]=w\left(t_{2}\right) \\
& <w\left(t_{1}\right)=\left\{u\left(t_{1}\right)\right\}^{m-1}\left[\left|v^{\prime}\left(t_{1}\right)\right|^{m-2} v^{\prime}\left(t_{1}\right)-\left|u^{\prime}\left(t_{1}\right)\right|^{m-2} u^{\prime}\left(t_{1}\right)\right] \leq 0,
\end{aligned}
$$

which gives a contradiction, too. Hence, there exists $t_{3} \in\left(t_{1}, t_{2}\right)$ such that $u\left(t_{3}\right)=$ $v\left(t_{3}\right)>0$. Repeating the same argument, we obtain a strictly decreasing sequence $\left\{t_{n}\right\}_{n=3}^{\infty} \subset\left(t_{1}, t_{2}\right) \subset\left(\theta_{1}, \theta_{2}\right)$ such that $t_{n} \in\left(t_{1}, t_{n-1}\right)$ and $u\left(t_{n}\right)=v\left(t_{n}\right)$ for all $n=3,4, \ldots$ By the Bolzano-Weierstrass theorem, we see that $\left\{t_{n}\right\}_{n=3}^{\infty}$ has an accumulation point, say $\eta$, in $\left[t_{1}, t_{2}\right]$. It is clear that $u(\eta)=v(\eta)>0$ and $u^{\prime}(\eta)=$ $v^{\prime}(\eta)>0$. Since $f(t, x, y)$ satisfies $(\mathrm{H})$, it follows from the uniqueness of the nonzero initial value problem that $u(t)=v(t)$ in $\left[\theta_{1}, \theta_{2}\right]$ (see, for example, Hartman [11]).

Theorem 2.3. The boundary value problem (E)-(BC.2) has at most one positive solution in $C^{1}\left(\left[\theta_{1}, \theta_{2}\right]\right)$.

Proof. Assume to the contrary that $u$ and $v$ are two distinct positive solutions of (E)-(BC.2). Just as in the proof of Theorem 2.2, we claim that $u$ and $v$ intersect in $\left(\theta_{1}, \theta_{2}\right)$. Suppose, on the contrary, that $u(t)>v(t)$ in $\left(\theta_{1}, \theta_{2}\right)$. It follows from Lemma 2.1 and $u^{\prime}\left(\theta_{2}\right) \leq v^{\prime}\left(\theta_{2}\right)(\leq 0)$ that

$$
\begin{aligned}
0 & \leq\left\{u\left(\theta_{2}\right)\right\}^{m-1}\left[\left|v^{\prime}\left(\theta_{2}\right)\right|^{m-2} v^{\prime}\left(\theta_{2}\right)-\left|u^{\prime}\left(\theta_{2}\right)\right|^{m-2} u^{\prime}\left(\theta_{2}\right)\right]=w\left(\theta_{2}\right) \\
& <w\left(\theta_{1}\right)=\left[\left\{u\left(\theta_{1}\right)\right\}^{m-1}-\left\{v\left(\theta_{1}\right)\right\}^{m-1}\right]\left|v^{\prime}\left(\theta_{1}\right)\right|^{m-2} v^{\prime}\left(\theta_{1}\right) \leq 0
\end{aligned}
$$

which gives a contradiction. Hence, there exists $t_{1} \in\left(\theta_{1}, \theta_{2}\right)$ such that $u\left(t_{1}\right)=$ $v\left(t_{1}\right)>0$. Since $u\left(t_{1}\right)=v\left(t_{1}\right)>0$ and $u^{\prime}\left(\theta_{2}\right)=v^{\prime}\left(\theta_{2}\right)=\xi_{2} \geq 0$, it follows from Theorem 2.2 that $u(t)=v(t)$ on $\left[t_{1}, \theta_{2}\right]$. Therefore, $u(t)=v(t)$ in $\left[\theta_{1}, \theta_{2}\right]$.

Theorem 2.4. The boundary value problem (E)-(BC.3) has at most one positive solution in $C^{1}\left(\left[\theta_{1}, \theta_{2}\right]\right)$.

Proof. Assume to the contrary that $u$ and $v$ are two distinct positive solutions of (E)-(BC.3). By virtue of Theorems 2.2 and 2.3, we see that $u^{\prime}\left(\theta_{1}\right) \neq v^{\prime}\left(\theta_{1}\right)$ and $u^{\prime}\left(\theta_{2}\right) \neq v^{\prime}\left(\theta_{2}\right)$. Without loss of generality, we may assume that $u(t)>v(t)$ in $\left(\theta_{1}, \theta_{2}\right)$. Thus $u^{\prime}\left(\theta_{1}\right)>v^{\prime}\left(\theta_{1}\right)$. Define $t_{1}$ and $t_{2}$ so that $u^{\prime}\left(t_{1}\right)=v^{\prime}\left(t_{2}\right)=0$. Similar to the proof of Lemma 2.1, we have that $t_{1}=t_{2}$. Applying Theorems 2.2 and 2.3, we obtain $u \equiv v$ on $\left[\theta_{1}, t_{1}\right]$ and $u \equiv v$ on $\left[t_{1}, \theta_{2}\right]$. Therefore, we obtain the desired results.

Theorem 2.5. The boundary value problem (BVP) has at most one positive solution in $C^{1}\left(\left[\theta_{1}, \theta_{2}\right]\right)$. 
Proof. Assume to the contrary that $u$ and $v$ are two distinct positive solutions of (BVP). We split the proof into the following cases.

Case (1). Assume that $\alpha_{1}=0$, that is, $u^{\prime}\left(\theta_{1}\right)=v^{\prime}\left(\theta_{1}\right)=0$. Since $\left|u^{\prime}\right|^{m-2} u^{\prime}$ and $\left|v^{\prime}\right|^{m-2} v^{\prime}$ are strictly decreasing in $\left(\theta_{1}, \theta_{2}\right), u^{\prime}(t)<0$ and $v^{\prime}(t)<0$ in $\left(\theta_{1}, \theta_{2}\right]$. Now, we claim that $u$ and $v$ intersect in $\left(\theta_{1}, \theta_{2}\right)$. Suppose to the contrary that $u(t)>v(t)>0$ in $\left(\theta_{1}, \theta_{2}\right)$.

$\left(1^{\circ}\right)$ If $\alpha_{2}=0$, then $u^{\prime}\left(\theta_{2}\right)=v^{\prime}\left(\theta_{2}\right)=0$. This contradicts the fact that $u^{\prime}(t)<0$ and $v^{\prime}(t)<0$ in $\left(\theta_{1}, \theta_{2}\right]$.

$\left(2^{\circ}\right)$ If $\beta_{2}=0$, then $u\left(\theta_{2}\right)=v\left(\theta_{2}\right)=0$. It follows from $u^{\prime}\left(\theta_{1}\right)=v^{\prime}\left(\theta_{1}\right)=0$, $u\left(\theta_{2}\right)=v\left(\theta_{2}\right)=0$ and Theorem 2.3 that $u(t)=v(t)$ on $\left[\theta_{1}, \theta_{2}\right]$, which gives a contradiction.

$\left(3^{\circ}\right)$ If $\alpha_{2} \beta_{2} \neq 0$, then $u^{\prime}\left(\theta_{2}\right) v\left(\theta_{2}\right)=v^{\prime}\left(\theta_{2}\right) u\left(\theta_{2}\right)$. It is clear that $u\left(\theta_{2}\right)>v\left(\theta_{2}\right)>$ 0 , and thus $u^{\prime}\left(\theta_{2}\right)<v^{\prime}\left(\theta_{2}\right)<0$. In fact, if $v\left(\theta_{2}\right)=0$ (resp. $u\left(\theta_{2}\right)=v\left(\theta_{2}\right)$ ), it follows from (BC) and $u^{\prime}\left(\theta_{2}\right) v\left(\theta_{2}\right)=v^{\prime}\left(\theta_{2}\right) u\left(\theta_{2}\right)$ that $u\left(\theta_{2}\right)=v\left(\theta_{2}\right) \geq 0$, with Theorem 2.3 gives a contradiction.

Repeating the similar argument in Case (1) of Lemma 2.1, we can see that $w(t)$ is strictly decreasing on $\left[\theta_{1}, \theta_{2}\right]$. Therefore, we obtain

$$
\begin{aligned}
0 & =(-1)^{m-2}\left[\left(v^{\prime}\left(\theta_{1}\right) u\left(\theta_{1}\right)\right)^{m-1}-\left(u^{\prime}\left(\theta_{1}\right) v\left(\theta_{1}\right)\right)^{m-1}\right]=w\left(\theta_{1}\right) \\
& >w\left(\theta_{2}\right)=(-1)^{m-2}\left[\left(v^{\prime}\left(\theta_{2}\right) u\left(\theta_{2}\right)\right)^{m-1}-\left(u^{\prime}\left(\theta_{2}\right) v\left(\theta_{2}\right)\right)^{m-1}\right]=0,
\end{aligned}
$$

which gives a contradiction.

Hence, there is $t_{2} \in\left(\theta_{1}, \theta_{2}\right)$ such that $u\left(t_{2}\right)=v\left(t_{2}\right)>0$. Since $u^{\prime}\left(\theta_{1}\right)=v^{\prime}\left(\theta_{1}\right)=$ 0 and $u\left(t_{2}\right)=v\left(t_{2}\right)>0$, it follows from Theorem 2.3 that $u(t)=v(t)$ on $\left[\theta_{1}, t_{2}\right]$. Therefore, $u(t)=v(t)$ in $\left[\theta_{1}, \theta_{2}\right]$.

Case (2). Assume that $\beta_{1}=0$, that is, $u\left(\theta_{1}\right)=v\left(\theta_{1}\right)=0$. It follows from $\left|u^{\prime}\right|^{m-2} u^{\prime},\left|v^{\prime}\right|^{m-2} v^{\prime}$ strictly decreasing in $\left(\theta_{1}, \theta_{2}\right)$ and $u\left(\theta_{1}\right)=v\left(\theta_{1}\right)=0$ that $u^{\prime}\left(\theta_{1}\right)>0$ and $v^{\prime}\left(\theta_{1}\right)>0$. Now, we claim that $u$ and $v$ intersect in $\left(\theta_{1}, \theta_{2}\right)$. Suppose to the contrary that $u(t)>v(t)>0$ in $\left(\theta_{1}, \theta_{2}\right)$, and this implies $u^{\prime}\left(\theta_{1}\right) \geq v^{\prime}\left(\theta_{1}\right)>0$.

$\left(4^{\circ}\right)$ If $\alpha_{2}=0$, then $u^{\prime}\left(\theta_{2}\right)=v^{\prime}\left(\theta_{2}\right)=0$. It follows from Theorem 2.2 that $u(t)=v(t)$ in $\left[\theta_{1}, \theta_{2}\right]$, which gives a contradiction.

$\left(5^{\circ}\right)$ If $\beta_{2}=0$, then $u\left(\theta_{2}\right)=v\left(\theta_{2}\right)=0$. It follows from Theorem 2.4 that $u(t)=v(t)$ in $\left[\theta_{1}, \theta_{2}\right]$, which gives a contradiction.

$\left(6^{\circ}\right)$ If $\alpha_{2} \beta_{2} \neq 0$, then $u^{\prime}\left(\theta_{2}\right) v\left(\theta_{2}\right)=v^{\prime}\left(\theta_{2}\right) u\left(\theta_{2}\right)$. Repeating the same argument in Case (1) of Lemma 2.1 (or cf. Case $(1)-\left(3^{\circ}\right)$ ), we see that $w(t)$ is strictly decreasing on $\left[\theta_{1}, \theta_{2}\right]$. Therefore, we obtain

$$
\begin{aligned}
0 & =\left\{u\left(\theta_{1}\right)\right\}^{m-1}\left[\mid\left(\left.v^{\prime}\left(\theta_{1}\right)\right|^{m-2} v^{\prime}\left(\theta_{1}\right)-\left|u^{\prime}\left(\theta_{1}\right)\right|^{m-2} u^{\prime}\left(\theta_{1}\right)\right]=w\left(\theta_{1}\right)\right. \\
& >w\left(\theta_{2}\right)=\left\{u\left(\theta_{2}\right)\right\}^{m-1}\left(\left|v^{\prime}\left(\theta_{2}\right)\right|^{m-2} v^{\prime}\left(\theta_{2}\right)\right)-\left(\left|u^{\prime}\left(\theta_{2}\right)\right|^{m-2} u^{\prime}\left(\theta_{2}\right)\right)\left\{v\left(\theta_{2}\right)\right\}^{m-1}=0,
\end{aligned}
$$

which gives a contradiction.

Hence, there is $t_{2} \in\left(\theta_{1}, \theta_{2}\right)$ such that $u\left(t_{2}\right)=v\left(t_{2}\right)>0$. Since $u\left(\theta_{1}\right)=v\left(\theta_{1}\right)=0$ and $u\left(t_{2}\right)=v\left(t_{2}\right)>0$, it follows from Theorem 2.4 that $u(t)=v(t)$ on $\left[\theta_{1}, t_{2}\right]$. Therefore, $u(t)=v(t)$ in $\left[\theta_{1}, \theta_{2}\right]$.

Just as in the proof of Cases (1)-(2), we can exclude the possibility of $\alpha_{2}=0$ or $\beta_{2}=0$.

Case (3). Assume that $\alpha_{1} \alpha_{2} \beta_{1} \beta_{2} \neq 0$, that is, $u^{\prime}\left(\theta_{i}\right) v\left(\theta_{i}\right)=v^{\prime}\left(\theta_{i}\right) u\left(\theta_{i}\right)$ for $i=1,2$. The rest of the proof is quite similar to the proofs in Cases $(1)-\left(3^{\circ}\right)$ and Cases $(2)-\left(6^{\circ}\right)$, so we omit the details.

By Cases (1)-(3), we obtain the desired results. 


\section{REMARKS AND EXAMPLES}

Recently, Gatica, Oliker and Waltman [7], Kwong [14], Naito [17], Brezis and Oswald [3], and Dalmasso [5] showed the following important results:

Theorem 3.A ([3, Theorem 1]). Consider the problem

$$
\left\{\begin{array}{l}
\Delta u+f(x, u)=0 \quad \text { in } \Omega, \\
u \geq 0, \quad u \neq 0 \quad \text { in } \Omega, \\
u=0 \text { on } \partial \Omega
\end{array}\right.
$$

and make the following assumptions:

$\left(\mathrm{A}_{1}\right)$ For a.e. $x \in \Omega$ the function $u \rightarrow f(x, u)$ is continuous on $[0, \infty)$ and the function $u \rightarrow f(x, u) / u$ is strictly decreasing in $(0, \infty)$.

$\left(\mathrm{A}_{2}\right)$ For each $u \geq 0$ the function $u \rightarrow f(x, u)$ belongs to $L^{\infty}(\Omega)$. Then, there exists at most one solution of (BVP.1) in $H_{0}^{1} \cap L^{\infty}(\Omega)$.

Theorem 3.B ([5, Theorem 1]). Let $f \in C^{1}([0, R] \times[0, \infty))$ satisfying

$\left(\mathrm{C}_{1}\right) u f_{u}(t, u)>f(t, u)$ for $(t, u) \in[0, R] \times[0, \infty)$, that is, $\frac{f(t, u)}{u}$ is strictly increasing in $u \in[0, \infty)$ for each fixed $t \in[0, R]$;

$\left(\mathrm{C}_{2}\right) f_{t}(u, u) \leq 0$ for $(t, u) \in[0, R] \times[0, \infty)$;

$\left(\mathrm{C}_{3}\right)$ there exists $u>0$ such that $f(R, u) \geq 0$. Then

(BVP.2)

$$
\left\{\begin{array}{l}
\left.u^{\prime \prime}(t)\right)+f(|t|, u(t))=0, \quad-R<t<R, \\
u(-R)=u(R)=0
\end{array}\right.
$$

has at most one positive solution in $C^{2}[-R, R]$.

Theorem 3.C ([7, Theorem 4.1]). Let $k \in\{1,2,3, \ldots\}, p \in(0,1)$ and $h \in$ $C([0,1) ;[0, \infty))$ such that

$$
0<\int_{0}^{1}(1-t)^{-p} h(t) d t<\infty
$$

Then

$$
u^{\prime \prime}(t)+\frac{k}{t} u^{\prime}(t)+h(t) u^{-p}(t)=0 \quad \text { in }(0,1)
$$

has at least one positive solution satisfying (BC.2) in $C^{1}[0,1] \cap C^{2}(0,1)$.

Theorem 3.D ([14, Theorem 2]). Assume that $q(t)>0$ in $(0,1)$ and $f(u) / u$ is decreasing in $(0, \infty)$ and not constant in any neighborhood of $u=0$. Then

$$
u^{\prime \prime}(t)+q(t) f(u(t))=0 \quad \text { in }(0,1)
$$

has a unique positive solution satisfying (BC.2) in $C^{1}[0,1] \cap C^{2}(0,1)$.

Theorem 3.E ([17, Theorems 1-3]). Let

$\left(\mathrm{B}_{1}\right) p \in C\left[\theta_{1}, \theta_{2}\right]$ and $p(t)>0$ in $\left(\theta_{1}, \theta_{2}\right)$;

$\left(\mathrm{B}_{2}\right) f \in C[0, \infty), f(u)>0$ in $(0, \infty)$ and $\frac{f(u)}{u^{m-1}}$ is decreasing in $u \in(0, \infty)$;

$\left(\mathrm{B}_{3}\right)$ for any $\lambda>0($ resp. $\lambda<0)$, a solution $u$ of

$$
\left(\left|u^{\prime}\right|^{m-2} u^{\prime}\right)^{\prime}+p(t) f(u)=0, \quad \theta_{1}<t<\theta_{2}, m \geq 2,
$$


satisfying $u\left(\theta_{1}\right)=0$ and $u^{\prime}\left(\theta_{1}\right)=\lambda$ (resp. $u\left(\theta_{2}\right)=0$ and $\left.u^{\prime}\left(\theta_{2}\right)=\lambda\right)$ is determined uniquely as long as $u^{\prime}(t)>0\left(\right.$ resp. $\left.u^{\prime}(t)<0\right)$.

Then, $\left(\mathrm{E}_{5}\right)$ has at most one positive solution in $C^{1}\left[\theta_{1}, \theta_{2}\right]$ satisfying (BC.1)(BC.3).

Remark 3.F. Comparing our uniqueness theorems with the above-mentioned results, we have the following remarks:

(I) The assumption " $u \rightarrow f(x, u)$ is continuous on $[0, \infty)$ " in Theorem 3.A implies $f(x, u) \neq u^{p}$ for $p<0$, and " $f(u) / u$ is decreasing in $(0, \infty)$ and is not a constant in any neighborhood of $u=0$ " in Theorem 3.D is imposed to exclude the situation in which $f(u)$ behaves like a linear function in a neighborhood of $u=0$, that is, $f(u) / u$ behaves like a strictly decreasing function near $u=0$.

(II) It is clear that if $f(t, u)$ is (strictly) decreasing in $u \in(0, \infty)$ and

$$
f(t, u) \equiv h(t) u^{-p}, h(t) u^{q}, u^{\alpha}+u^{-\alpha}, \sin (t) u^{-p}+\cos (t) u^{q}
$$

for any given $p \in[0, \infty), q \in[0, m-1), \alpha \in[0, m-1]$ and $h \in C((0,1) ;[0, \infty))$, then $f(t, u)$ satisfies " $f(t, u) / u^{m-1}$ is strictly decreasing in $u$ ". But Theorems 3.A, 3.C, 3.D and 3.E cannot be applied to most of these functions, for example,

$$
f(t, u) \equiv u^{1 / 2}, u^{-1}+u \text { and } t u^{\frac{1}{3}}+e^{t} u^{\frac{1}{2}} .
$$

Furthermore, Theorem 3.C does not tell us "the uniqueness of positive solution of $\left(\mathrm{E}_{3}\right)$ with (BC.2)".

(III) Our main results generalize Theorems 3.A, 3.C, 3.D, 3.E and also confirm the uniqueness of Theorem 3.C.

(IV) The excellent uniqueness Theorem 3.B of Dalmasso [5] combines with the main results in this article. They can criticize almost all the uniqueness of positive solutions of (E)-(BC. $i)(i=1,2,3)$ and (BVP).

Example 3.G. (I) It follows from Theorem 2.2 (resp. Theorems 2.3, 2.4, 2.5) that the boundary value problem

(BVP.3)

$$
\left\{\begin{array}{l}
\left(\left|u^{\prime}\right|^{m-2} u^{\prime}\right)^{\prime}+2[t(1-t)]^{2} u^{-p}+\frac{\sin (t)\left|u^{\prime}\right|^{\frac{-1}{3}}}{1+t^{2}}=0 \quad \text { in }(0,1) \\
u(0)=u^{\prime}(1)=0 \\
\left(\text { resp. } u^{\prime}(0)=u(1)=0, u(0)=u(1)=0, u(0)=u(1)+2 u^{\prime}(1)=0\right)
\end{array}\right.
$$

has at most one positive solution in $C^{1}[0,1]$, where $p \in(0, \infty)$.

(II) It follows from Theorem 2.3 (resp. Theorems 2.2, 2.4, 2.5) that the boundary value problem

(BVP.4)

$$
\left\{\begin{array}{l}
\left(\left|u^{\prime}\right|^{m-2} u^{\prime}\right)^{\prime}+\frac{1}{1+t^{2}} u^{p}=0 \text { in }(0,1), p \in(-\infty, m-1) \\
u^{\prime}(0)=u(1)=0 \\
\left(\text { resp. } u(0)=u^{\prime}(1)=0, u(0)=u(1)=0, u(0)=u(1)+2 u^{\prime}(1)=0\right)
\end{array}\right.
$$

has at most one positive solution in $C^{1}[0,1]$. 
(III) It follows from Theorem 2.4 (resp. Theorems 2.2, 2.3, 2.5) that the boundary value problem

(BVP.5) $\left\{\begin{array}{l}\left(\left|u^{\prime}\right|^{m-2} u^{\prime}\right)^{\prime}+\frac{1}{t^{\alpha+1}}\left(u^{\alpha}+u^{-\alpha}\right)+\cos (t)\left|u^{\prime}\right|^{-\beta}=0 \quad \text { in }(0,1), \\ u(0)=u(1)=0 \\ \left(\operatorname{resp} . u(0)=u^{\prime}(1)=0, u^{\prime}(0)=u(1)=0, u(0)=u(1)+2 u^{\prime}(1)=0\right)\end{array}\right.$

has at most one positive solution in $C^{1}[0,1]$, where $\alpha \in[0, m-1], \beta>0$.

\section{REFERENCES}

[1] R. P. Agarwal and V. Lakshmikantham, Uniqueness and nonuniqueness criteria for ordinary differential equations, World Scientific, Singapore, 1993. MR 96e:34002

[2] L. E. Bobisud, Steady state turbulent flow with reaction, Rocky Mount. J. Math. 21 (1991), 993-1007. MR 93a:34026

[3] H. Brezis and L. Oswald, Remarks on sublinear elliptic equations, Nonlinear Analysis T. M. \& A. 19 (1986), 55-64. MR 87c:35057

[4] R. Dalmasso, Uniqueness of positive and nonnegative solutions of nonlinear equations, Funkcial. Ekvac 37 (1994), 461-482. MR 97c:34037

[5] U Uniqueness of positive solutions of nonlinear second-order equations, Proc. Amer. Math. Soc. 123 (1995), 3417-3424. MR 96a:34035

[6] D. De. Figueiredo, P. L. Lions and R. Nussbaum, A priori estimates and existence of positive solutions of semilinear elliptic equations, J. Math. Pures. App. 61 (1982), 41-63. MR 83h:35039

[7] J. A. Gatica, V. Oliker and P. Waltman, Singular nonlinear boundary value problems for second-order ordinary differential equations, 79 (1989), 62-78. MR 90f:34030

[8] B. Gidas, W. M. Ni and L. Nirenberg, Symmetry and related properties via the maximum principle, Comm. Math. Phys. 68 (1979), 209-243. MR 80h:35043

[9] A. Granas, R. B. Guenther and J. W. Lee, Nonlinear boundary value problems for ordinary differential equations, Dissertationes (Rozprawy Mat) 244 (1985). MR 87a:34025

[10] M. Guedda and L. Veron, Bifurcation phenomena associated to the p-Laplace operator, Trans. Amer. Math. Soc. 310 (1988), 419-431. MR 89j:35024

[11] P. Hartman, Ordinary differential equations, Birkhauser, Boston, 1982. MR 83e:34002

[12] H. G. Kaper, M. Knapp and M. K. Kwong, Existence theorems for second order boundary value problems, Differential Integral Equations 4 (1991), 543-554. MR 92m:34059

[13] M. Krasnoselskii, Positive solutions of operator equations, Noordhoff, Groningen, 1964. MR 31:6107

[14] M. K. Kwong, On the Kolodner-Coffman method for the uniqueness problem of EmdenFowler BVP, Z. Angew. Math. Phys. 41 (1990), 79-104. MR 91b:34037

[15] Uniqueness of positive solutions of $\Delta u-u+u^{p}=0$ in $\mathbb{R}^{n}$, Arch. Rational. Mech. Anal. 105 (1989), 243-266. MR 90d:35015

[16] P. L. Lions, On the existence of positive solutions of semilinear elliptic equations, SIAM Rev. 24 (1982), 441-467. MR 84a:35093

[17] Y. Naito, Uniqueness of positive solutions of quasilinear differential equations, Differential Integral Equations 8 (1995), 1813-1822. MR 96g:34039

[18] W. M. Ni and R. Nussbaum, Uniqueness and nonuniqueness for positive radial solutions of $\Delta u+f(r, u)=0$, Comm. Pure. Appl. Math. 38 (1985), 69-108. MR 86d:35055

[19] M. del Pino, M. Elgueta and R. Manasevich, A homotopic deformation along $p$ of a LeraySchauder degree result and existence for $\left(\left|u^{\prime}\right|^{p-2} u^{\prime}\right)^{\prime}+f(t, u)=0, u(0)=u(T)=0, p>1$, J. Differential Equations 80 (1989), 1-13. MR 91i:34018

[20] M. del Pino and R. Manasevich, Multiple solutions for the p-Laplacian under global nonresonance, Proc. Amer. Math. Soc. 112 (1991), 131-138. MR 91h:34026

[21] P. H. Rabinowitz, Minmax methods in critical point theory with applications to differential equations, CBMS Regional Conf. Ser. in Math., Amer. Math. Soc., Providence, RI, 1986. MR 87j:58024

[22] Donal O'Regan, Theory of singular boundary value problems, World Scientific, Singapore, 1994. MR 95g:34003 
[23] F. H. Wong and S. L. Yu, Uniqueness of positive solutions for singular nonlinear boundary value problems, Hiroshima Mathematical Journal 26 (1996), 233-243. MR 97d:35044

[24] F. H. Wong, Existence of positive solutions of singular boundary value problems, Nonlinear analysis T.M. \& A. 21 (1993), 397-406. MR 94i:34056

Department of Mathematics and Science, National Taipei Teacher's College, 134, Ho-Ping E. Rd. Sec. 2, Taipei 10659, Taiwan, Republic of China

E-mail address: wong@tea.ntptc.edu.tw 